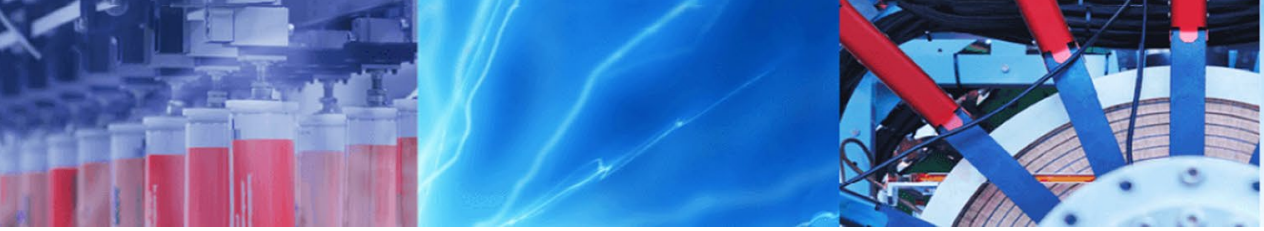

Research Article

\title{
Effect of variable infill density on mechanical behaviour of 3-D printed PLA specimen: an experimental investigation
}

\author{
Md. Qamar Tanveer ${ }^{1}\left[\right.$ (]) Abid Haleem ${ }^{1} \cdot$ Mohd Suhaib $^{1}$
}

Received: 22 October 2019 / Accepted: 20 November 2019 / Published online: 27 November 2019

(c) Springer Nature Switzerland AG 2019

\begin{abstract}
Fused deposition modelling (FDM) is one of the additive manufacturing technique, widely accepted due to its 'easy to use' technology. The set process parameters during FDM printing, affect the mechanical behaviour of the built part. The objective of this study is to investigate the effect of variable infill density on the tensile and impact strength of polylactic acid (PLA) specimens printed by an open-source 3D printer. The tensile and impact test specimens are printed according to the DIN EN ISO 527-2, ASTM D256 (Izod) and ASTM D6110 (Charpy) respectively. A computerised tensometer and impactometer used to conduct the tensile and the impact strength of the PLA specimens. The tensile strength with the highest value of $46.3 \mathrm{~N} / \mathrm{mm}^{2}$ and the lowest value of $29.9 \mathrm{~N} / \mathrm{mm}^{2}$ are found. The results demonstrate that the specimens with varying infill density exhibit better tensile strength than the specimens with single infill density. The varying infill density specimens weigh lighter as compared to single infill density, which saves the raw material. The highest Charpy and lowest lzod strength found to be $4.72 \mathrm{~kJ} / \mathrm{m}^{2}$ and $1.7 \mathrm{~kJ} / \mathrm{m}^{2}$. The impact test experimental data establishes that impact strength is directly proportional to the infill density. Thus, by varying the infill density, there is a reduction in the impact strength of the printed specimens.
\end{abstract}

Keywords FDM $\cdot$ PLA $\cdot$ Infill density $\cdot$ Tensile properties $\cdot$ Impact strength

\section{Introduction}

Fused deposition modeling (FDM), is an additive manufacturing (AM) technology used for printing three-dimensional part. It is based on the extrusion process where heated thermoplastic filament is "selectively dispensed through a nozzle or orifice" [1]. FDM is less expensive and easier to maintain as compared to other AM printing technologies and has a lower cost of hardware maintenance [2]. FDM seems to be a useful process for domestic as well as small industrial learning. It cannot be denied that FDM performance such as system cost, build time, raw material used, and waste are better, when compared with other AM techniques $[3,4]$.

Product developed through FDM process is mainly used to understand the three-dimensional complex and undertake simple prototypes [5]. Along with visual aid, it is also essential to evaluate the mechanical behaviour of the three dimensional (3D) printed part when subjected to various mechanical loads. Hence, the investigation of the mechanical behaviour of 3D printed parts is a subject of importance and research [6].

Various studies have been done on the process parameters to enhance mechanical properties. The primary process parameters which influence FDM are raster angle, build orientation, layer thickness, infill density and raster gap. Considering these factors, Sood et al. [7], studied their influence on impact, flexural and tensile strengths of FDM specimen. Empirical models developed, relating response and process parameters and the developed model were tested using the ANOVA technique. Masood et al. studied the process parameters such as air gap, raster angle and

Md. Qamar Tanveer, mohdqamar26@gmail.com | 'Department of Mechanical Engineering, Jamia Millia Islamia, New Delhi, India. 
raster width on the FDM part and compared the tensile properties with moulded specimens. The results show that the tensile strength of the FDM part is $70-75 \%$ of the moulded part [8]. Li et al. [9] used open-source FDM printer to study the effect bonding degree on the tensile strength of the PLA specimen. The result showed that bonding strength effects significantly by layer thickness, followed by deposition velocity.

Tymrak et al. compared the tensile properties of polylactic acid (PLA) and acrylonitrile butadiene styrene (ABS) on an open-source 3D printer. The parameters considered for the study were raster angle and layer height [10]. Cantrell et al. compared the tensile properties as well as shear properties of PLA and ABS on two different commercially available printers. The result indicated that build orientation and raster had a negligible effect on tensile specimens. ABS specimen shows shear yield strength varied by up to $33 \%$ [11]. Ziemian et al. studied five different mechanical properties of ABS specimen: compression, tension, 3-point bending, impact and fatigue, considering build orientation and raster angle. The results show that specimens build with raster angle direction parallel to applied force gives better mechanical properties [12]. Few authors studied the effect of Temperature, print speed, infill direction, relative density, and layer thickness on the PLA specimen and developed an empirical formula to optimise the process parameter [13-16]. Authors studied the impact of print orientation $[17,18]$, filament recycled PLA [19] on the mechanical properties of FDM developed parts. Lanzotti et al. used an open-source 3D printer to study the effect of layer thickness, the number of shell perimeters and infill orientation of PLA specimen. The results were prepositioned with an empirical model to understand the impact of each process parameter [20]. However, by scrutinising literature, it is found that the display of mechanical properties of specimen produced with PLA exhibits better results as compared to ABS specimen [21]. During the review, it is found that there are very few papers on the mechanical behaviour of PLA parts processed by lowcost 3D printers. Mainly, the parameter used during slicing aspect calls for further research. This study will focus on the effect of variable infill density, and their combination on the tensile strength and impact strength of 3D printed PLA specimen. The experimental data of the variable infill density also compared with single infill density specimen. The purpose of this study is to improve our understanding of optimal infill density and assist users in the selection of correct combination. It is crucial to get an optimum strenght to weight ratio. The understanding build during work done by various researchers is that the mechanical strength is directly proportional to the infill density. However, if the structure is large, 100\% fill density will increase the raw material and built time increasing printing cost.
In industry-standard practice, to save the build time and the running cost, higher shell perimeter and reduced in infill density is opted, which subsequently reduces the mechanical properties of the FDM parts.

\section{Materials and methods}

In the present study, a total of thirty-six number of specimens for tensile test, twenty-seven number of specimens for Izod and Charpy test printed by FDM technique, respectively. A set of three infill density percentage considered for the experimental work. A set of four specimens of tensile test and a set of three for Izod and Charpy test printed by fixing one infill density respectively. The sample preparation and testing of the specimen discussed in subsequent section as follows.

\subsection{Sample preparation}

This study focuses on the effect of varying infill density on the mechanical properties of the 3D printed parts. The printing of specimens is done by considering the combination of three different infill densities. Infill density is mainly categorised in three classifications: $A=100 \%$, $\mathrm{B}=75 \%, \mathrm{C}=50 \%$. The width of the layer is one-third of the total gauge width of the specimen. A total of nine categories designed by considering the possible combination of mentioned infill density shown in Table 1 . The variation of infill density decided in a manner that the external force applies to all the different infill density simultaneously. The orientation of the variation of infill is perpendicular to the applied force shown in Fig. 1.

The specimens initially modelled and converted to .STL file using $\mathrm{Creo}^{\circ}$ Software. An open-source Prusa I3 printer used to print the specimens. The hardware is bridged by software with the assistant of Repetier freeware 3D

Table 1 Infill Density Arrangement

\begin{tabular}{llccc}
\hline S. no. & Classification & \multicolumn{3}{c}{ Infill density percentage } \\
\cline { 3 - 5 } & & Outer layer & Inner layer & Outer layer \\
\hline 1 & A & 100 & 100 & 100 \\
2 & B & 75 & 75 & 75 \\
3 & C & 50 & 50 & 50 \\
4 & ABA & 100 & 75 & 100 \\
5 & BAB & 75 & 100 & 75 \\
6 & ACA & 100 & 50 & 100 \\
7 & CAC & 50 & 100 & 50 \\
8 & BCB & 75 & 50 & 75 \\
9 & CBC & 50 & 75 & 50 \\
\hline
\end{tabular}


Fig. 1 Arrangement of infill density
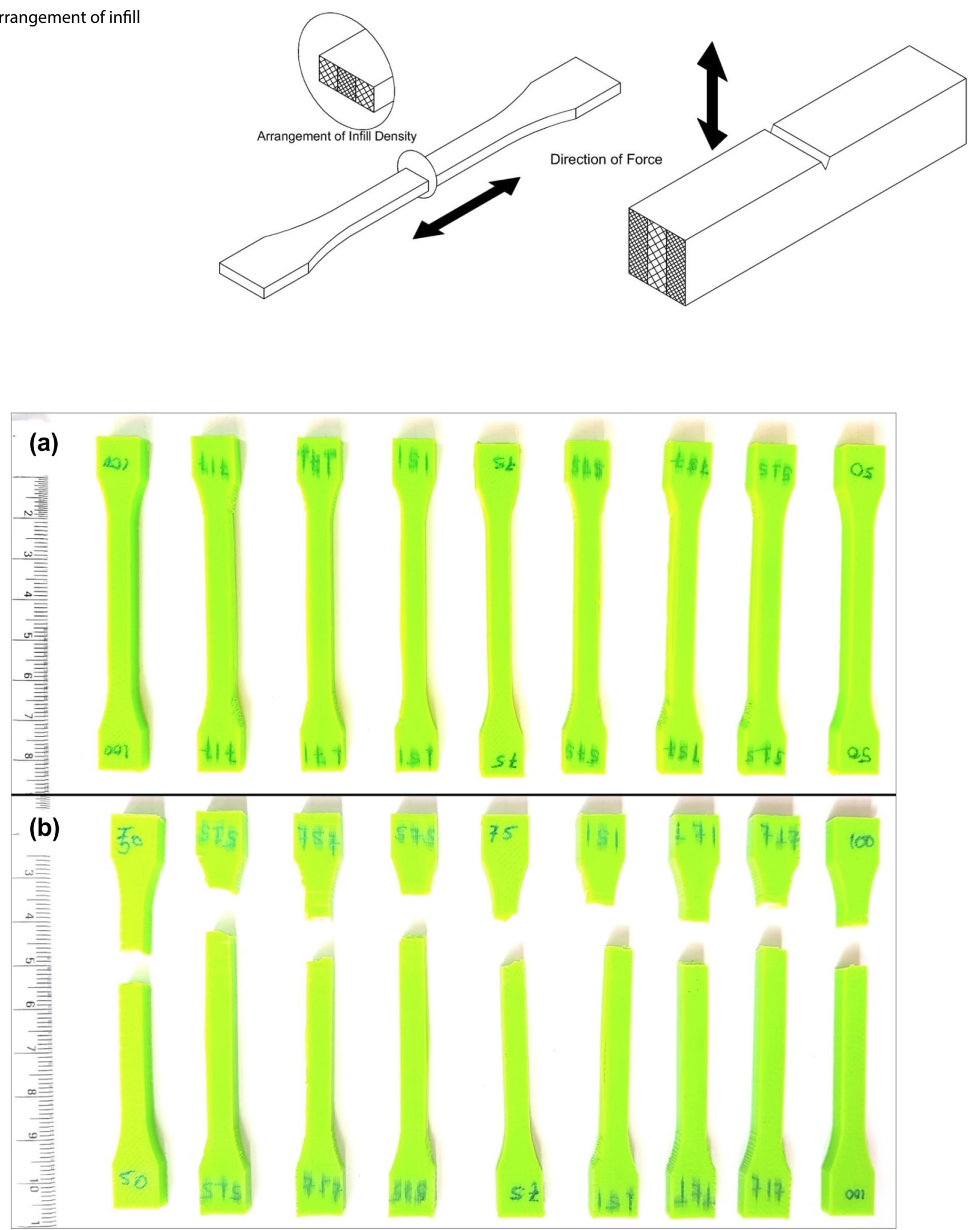

Fig. 2 Tensile test specimens, $\mathbf{a}$ before experiment, $\mathbf{b}$ after the experiment 
printing application. PLA filament, with a diameter of $1.74 \mathrm{~mm}$, is used to print the specimen. For the tensile test, dog-bone specimens printed according to ISO 527 (see Fig. 2). Impact test specimens printed according to ASTM D256 for Izod and ASTM D6110 for Charpy (see Fig. 3). Details of print conditions for the specimens shown in Table 2.

\subsection{Testing}

The electronic weighing machine with least count of $0.01 \mathrm{~g}$ is used to determine of the weight of specimen. The tensile test is conducted on computerised tensometer KIPL PC 20009 (see Fig. 4) with a least count and accuracy of $0.5 \%$ and $1 \%$ respectively. The range of the load cell of the apparatus is from 0.2 to $20 \mathrm{KN}$. The impact test was done on Saumya Izod/Charpy Impacto Meter (see Fig. 5) with least count $0.1 \%$, and the maximum energy of 25 Joule can be applied. The apparatus is available in the Department of Mechanical Engineering, Jamia Millia Islamia, New Delhi.
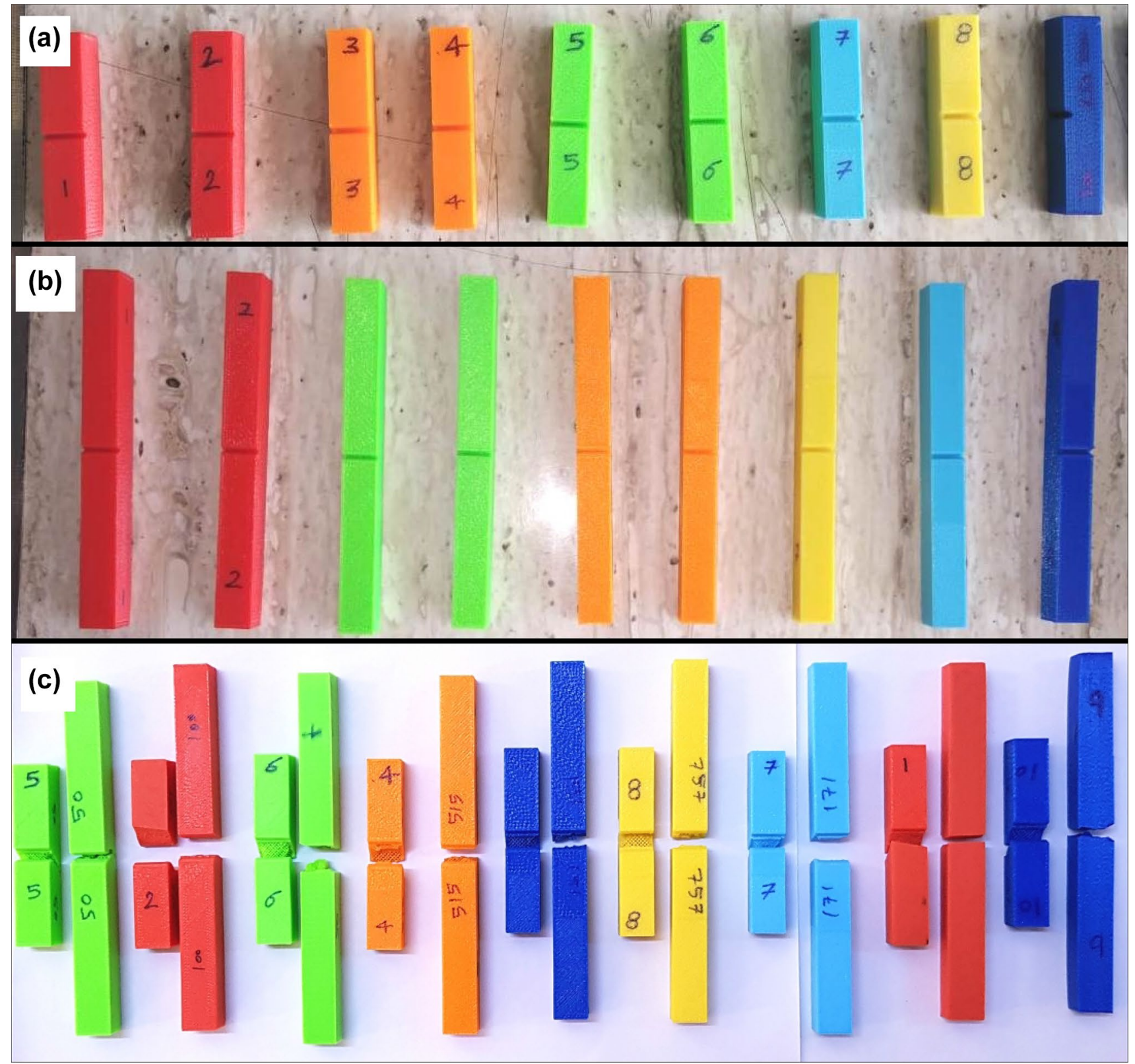

Fig. 3 Impact test specimens, a lzod test specimen, b Charpy test specimen, $\mathbf{c}$ specimens after the experiment 
Table 2 Parameters used for a 3D printer for PLA

\begin{tabular}{ll}
\hline Parameters & Values \\
\hline Nozzle temperature & $220^{\circ} \mathrm{C}$ \\
Bed temperature & $60^{\circ} \mathrm{C}$ \\
Nozzle diameter & $0.4 \mathrm{~mm}$ \\
Layer thickness & $0.2 \mathrm{~mm}$ \\
Print speed & $40 \mathrm{~mm} / \mathrm{s}$ \\
Infill structure & Line \\
Infill density & $50 \%, 75 \%, 100 \%$ \\
& and combina- \\
& tions \\
Raster angle & $\pm 45^{\circ}$ \\
\hline
\end{tabular}

\section{Result}

This study demonstrates the mechanical behaviour of the 3D printed part under two different test conditions, mainly tensile test and impact test. The criterion for the selection of test is to understand the response of PLA fibres in two diverse test conditions. Firstly, the direction of the applied force is parallel of 3D printed fibres in the tensile test and perpendicular in case of impact test. Next, the parallel forces try to elongate the fibre, whereas perpendicular forces will try to bend the fibres before failure. And lastly, the performance of fibres with the change in the duration of applied forces, i.e. gradual loading and impact loading.
Figure 6 shows the break load and peak load along with weight vs infill density of specimens. The value of the break and the peak load of specimen $C$ found to be least, which is $686.5 \mathrm{~N}$ and $725.7 \mathrm{~N}$, respectively. The highest value for specimen $\mathrm{A}$ which found to be $1088.6 \mathrm{~N}$ and $1127.8 \mathrm{~N}$ respectively among the single infill density specimen $A, B$ and $C$. From the experimental data, it is evident that ability to bear load increases with the positive incremental change in the infill density. Through the result it is found that the maximum break and peak load among the specimens of combined infill density is $1000.3 \mathrm{~N}$ and $1122.9 \mathrm{~N}$ in specimen $A B A$. The specimen $C B C$ exhibits least break and peak load value which is $779.7 \mathrm{~N}$ and $872.85 \mathrm{~N}$. The experimental data set helps to understand that during the failure of the specimen, the crack propagates from the outer shell to inside layer. This occurrence is better explained in the later section. The difference in the sequence of layering of the filling density is of one of the significant factors on the tensile property.

Figure 7 shows the percentage elongation during the experiment before the final breakage/separation of the specimens. The peak displacement is the elongation within the specimen before the breakage of the internal structure whereas, break displacement is the elongation after the first crack initiate until the final separation of the specimen. The maximum break displacement percentage found in specimen $A$, which is $5.1 \%$. The experimental data shows that the specimen $A$ with dense infill density, i.e. $100 \%$ shows maximum resistance against breakage. The compressed PLA fibres layer binds well with adjacent

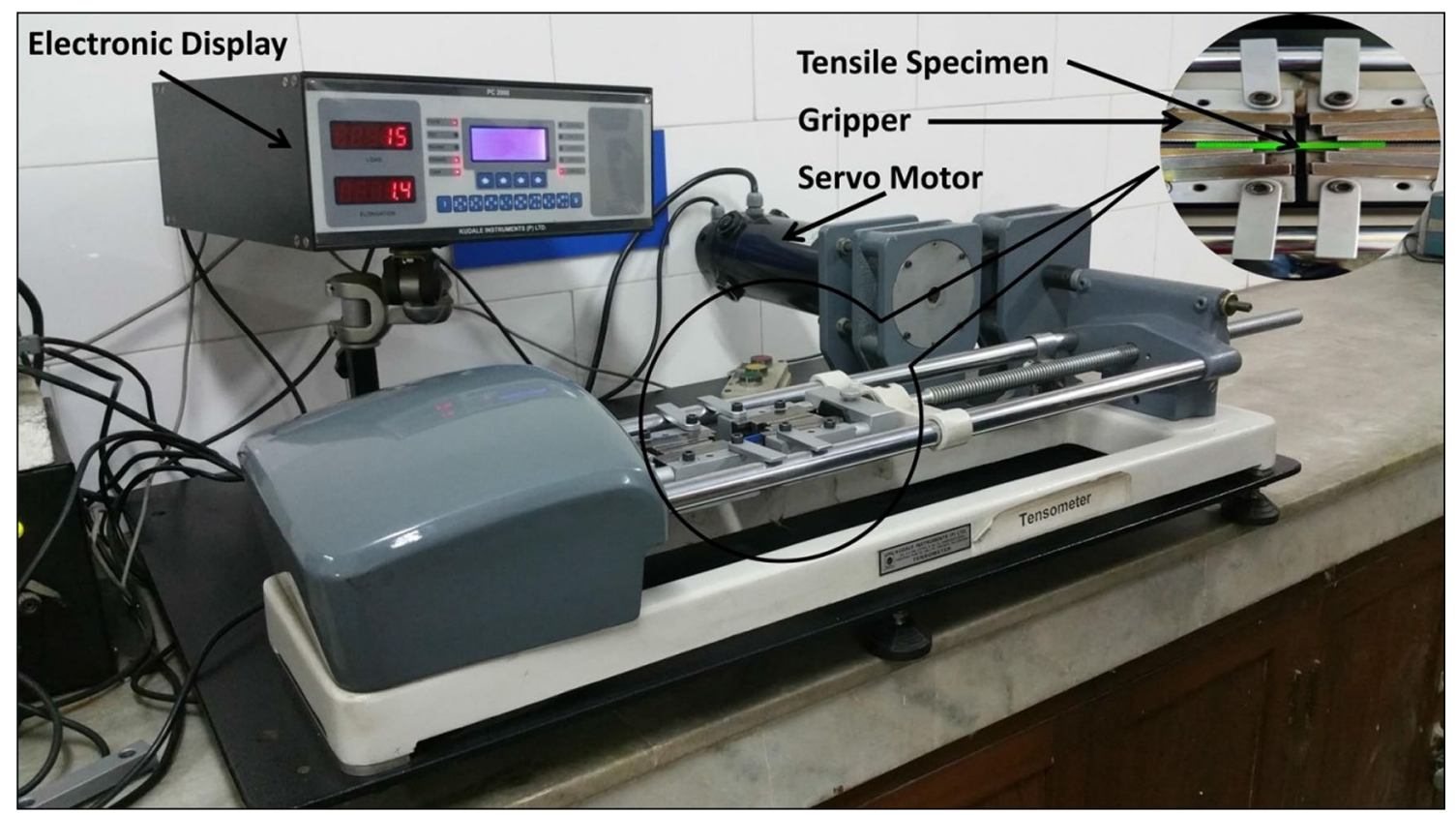

Fig. 4 Computerised tensometer KIPL PC 20009 and gripping of tensile specimen 


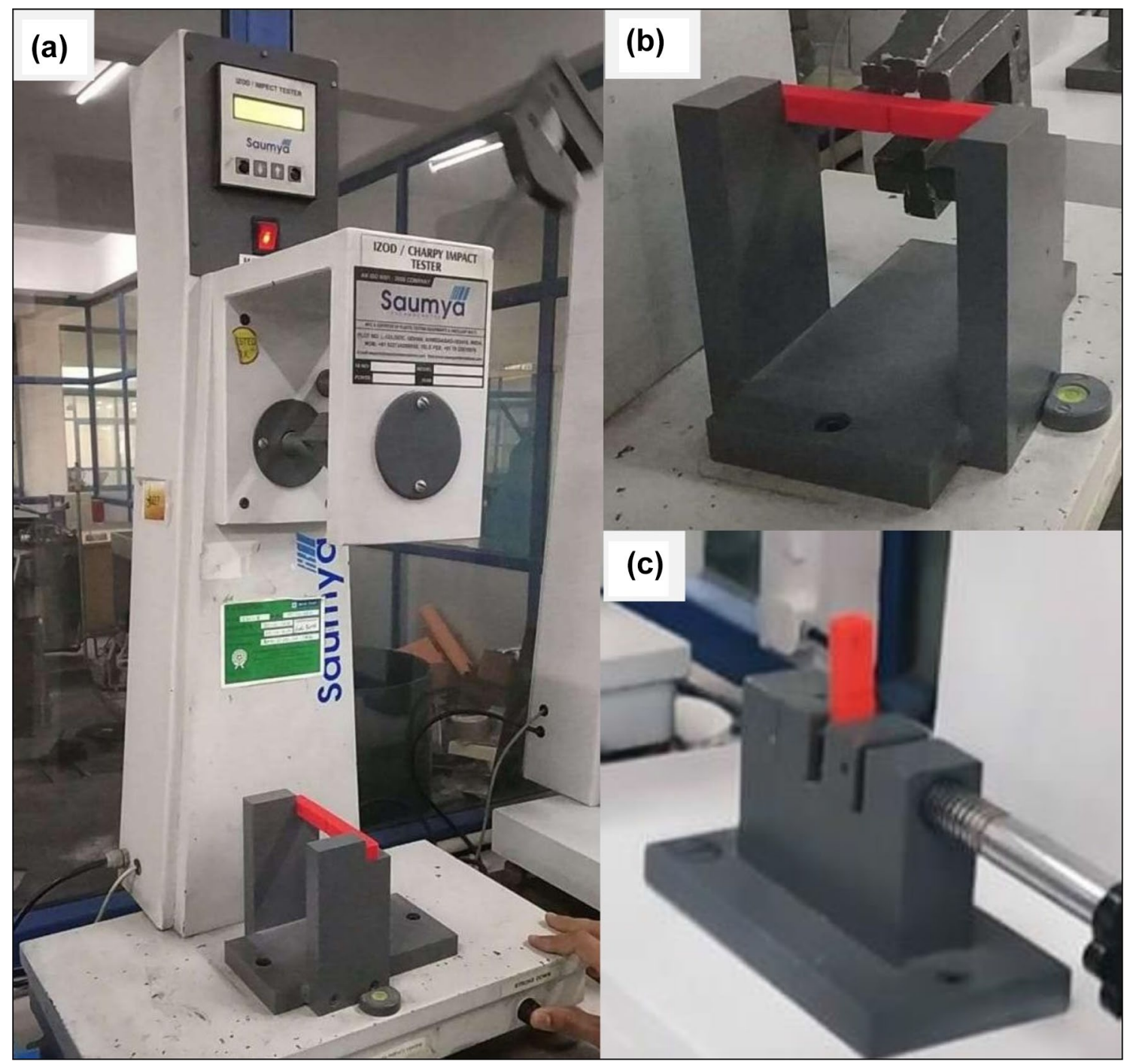

Fig. 5 a Impactometer apparatus, b placement of Charpy specimen, c placement of Izod specimen

layers which eventually make the structure strong enough to withhold the tensile force. The result displays that the dense infill exhibits higher resistance to break, but the less dense infill shows greater flexibility, which helps to increase the peak displacement. The specimen ABA displays maximum peak displacement of $4.17 \%$. The specimens $A B A, A C A$ and $B C B$ with less dense infill density inner layer and dense infill density shell outside display better than specimens $B A B, C A C$ and $C B C$ with dense infill density inner layer and less dense infill density shell outside. The $100 \%$ infill density arrangement gives higher resistance to crack propagation from the outer shell whereas; less dense inside layers provide more flexibility to improve the span of the affected structure of 3D printed part before failure.

Figure 8 shows the engineering tensile strength and true tensile strength of the specimens. For discussion, true tensile strength is considered. Specimen ABA shows the max tensile strength $\left(46.3 \mathrm{~N} / \mathrm{mm}^{2}\right)$, which is slightly higher than specimen $A$, which is found to be $45.1 \mathrm{~N} / \mathrm{mm}^{2}$. The dense structure gives a better resistance but fails at comparatively lesser load due to lack of flexibility between the compact arrangement of the layers of PLA fibre. The major factor for the increase of the tensile strength of variable infill density is that outer layers provide resistance for the 
Fig. 6 Comparison of break and peak load during the tensile test

Fig. 7 Comparison of break and peak displacement percentage during the tensile test

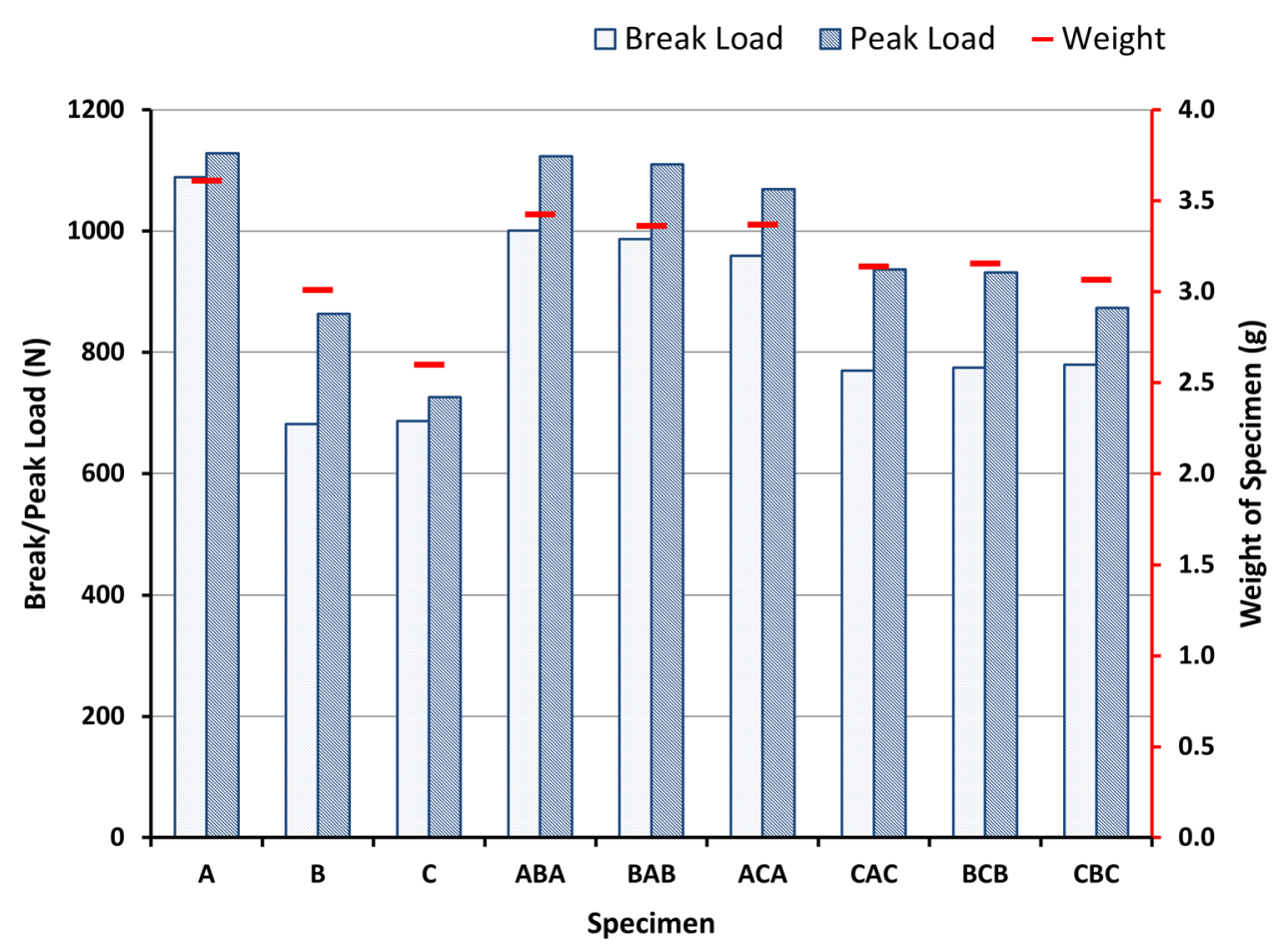

$\square$ Peak Disp. \% $₫$ Break Disp. \% - Weight

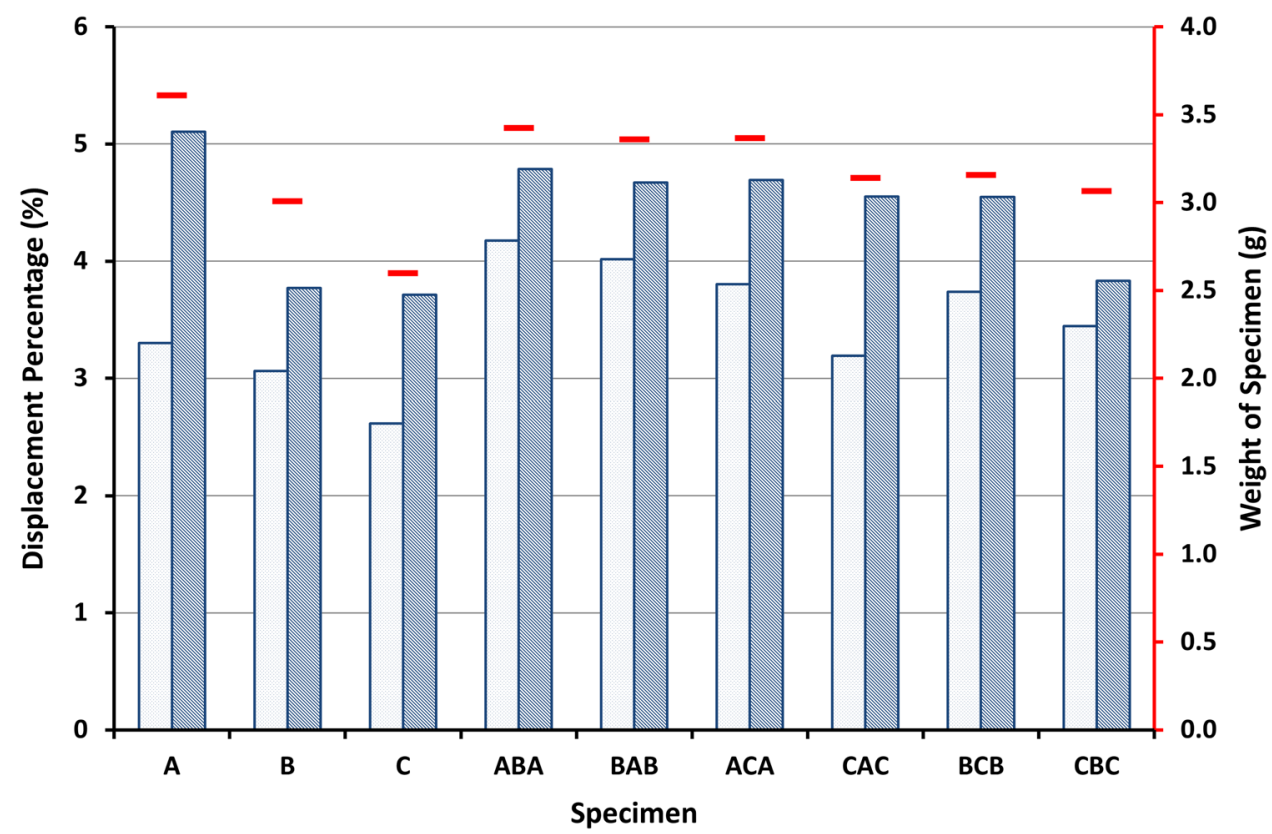

crack propagation from the outside due to dense structure and inner layers deliver better flexibility from deformation before ultimate failure. The specimen $C$ represents the least tensile strength $\left(29.9 \mathrm{~N} / \mathrm{mm}^{2}\right)$, which is understandable. In the case of single infill density of the specimens, the tensile strength increases with increase in the infill density. The specimens with variable infill density show interesting results. When the positions of infill density interchanged, the specimens $A B A, A C A$ and $B C B$ with dense infill density at outer layer show better tensile as compared to the specimens $B A B, C A C$ and $C B C$ with dense infill density at inner layer respectively. When the infill density at the outer layers are $100 \%$ as in the case of specimens ABA and ACA, the tensile strength when compared to the specimen to 
Fig. 8 Comparison of engineering tensile strength and true tensile strength of the tensile specimen

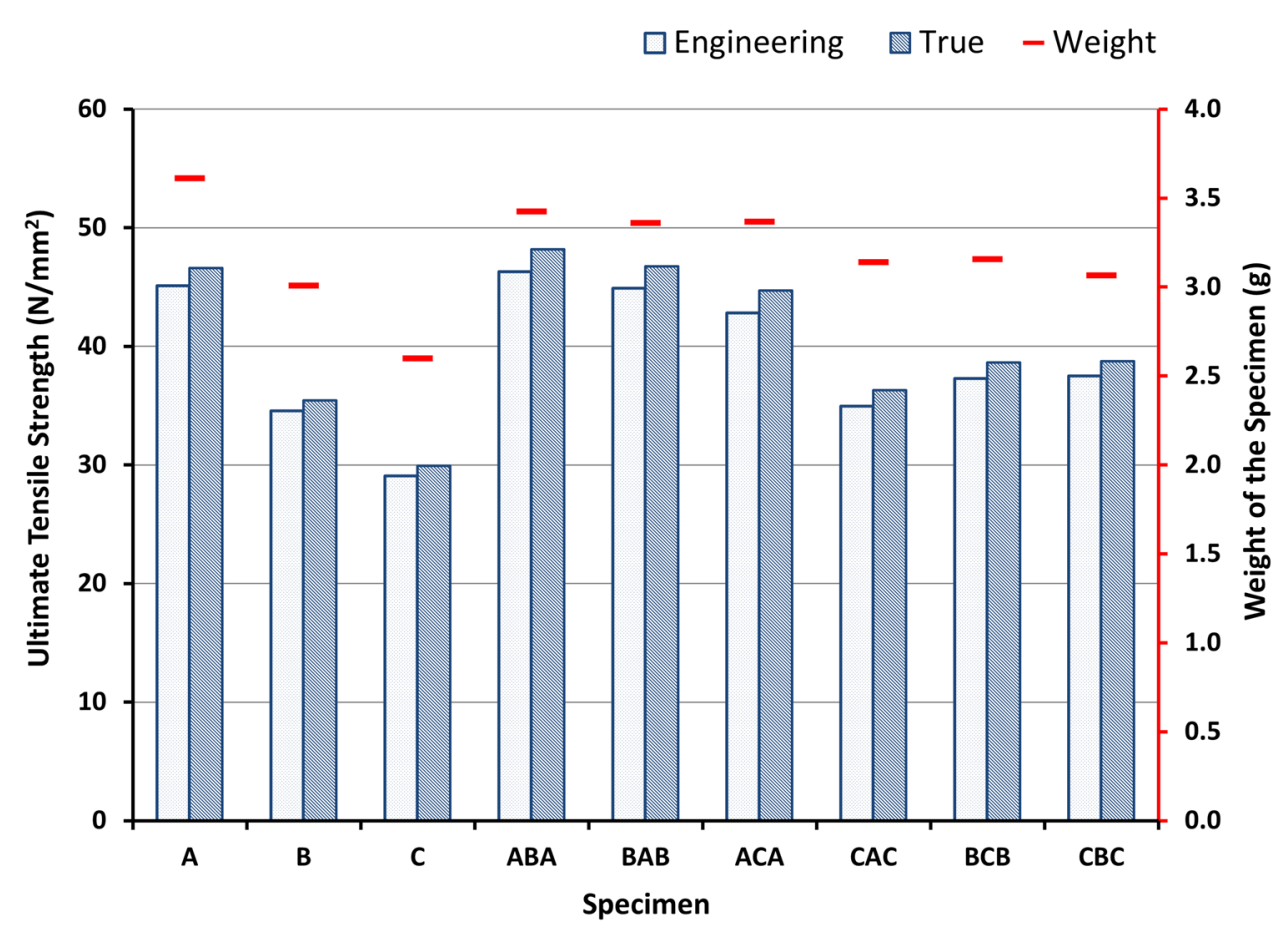

single infill density specimen $A$ is slightly more or less. The specimen $B C B$ and $C B C$ with a combination of infill density of $50 \%$ and $75 \%$ display higher tensile strength than single infill density of $75 \%$ which support the assumption of flexibility at inner layers due to varying infill density.

The weight of the specimens is also considered to find the optimum weight to strength ratio. The experimental data shows that a better tensile strength achieved with the use of lesser raw material. The specimen ABA displays tensile strength of $48.2 \mathrm{~N} / \mathrm{mm}^{2}$ with $3.42 \mathrm{~g}$ of weight which comparatively better than specimen $A\left(46.6 \mathrm{~N} / \mathrm{mm}^{2}\right)$ with a weight of $3.60 \mathrm{~g}$. This difference seems less as the specimens are small but will drastically if the size of the $3 D$ printed part increases. The results also show that the tensile strength of specimens ACA $\left(44.7 \mathrm{~N} / \mathrm{mm}^{2}\right)$ and $B A B$ $\left(46.75 \mathrm{~N} / \mathrm{mm}^{2}\right)$ is approximately equivalent to specimen $A$ $\left(46.6 \mathrm{~N} / \mathrm{mm}^{2}\right)$ with lesser weight which is $3.36 \mathrm{~g}$ and $3.35 \mathrm{~g}$ compared to $3.60 \mathrm{~g}$ respectively. The two major factors considered for lesser material weight during the printing of the 3D part are the selection of appropriate combinations of infill density and their position.

Figure 9 shows the experimental data of Izod and Charpy impact test. The dimensions of the Izod impact test specimen is approximately half of the Charpy impact specimen, which results in approximately fifty per cent reduction in weight. The Charpy impact strength is overall $10 \%$ greater than Izod impact strength of specimens made by the same perimeter. The orientation and support of the specimens are a significant factor for better impact strength in case of Charpy. Specimen A shows the maximum Izod and Charpy impact strength of $4.2 \mathrm{~kJ} /$ $\mathrm{m}^{2}$ and $4.72 \mathrm{~kJ} / \mathrm{m}^{2}$, respectively. The least value Izod and Charpy impact strength of $1.7 \mathrm{~kJ} / \mathrm{m}^{2}$ and $1.9 \mathrm{~kJ} / \mathrm{m}^{2}$ found in specimen BCB. The results represent that infill density plays a vital role in the impact strength. The impact strength depletes by varying the infill density between the layers. Interestingly, the results of impact test display a trend that the specimens $B A B, C A C$ and $C B C$ with dense infill density inside layers exhibit superior impact resistance compared to specimens $A B A, A C A$ and $B C B$ with less dense infill density inside layers.

The results show that higher the infill density, better the impact strength. There is significant deprivation of impact strength by lowering the infill density or by combining the variable infill density. Hence it can be stated that weight is directly proportional to the impact strength - the optimum weight of the raw material not found as in case of tensile test.

\section{Discussion}

The effect of variable infill density on the strength of specimen considering weight is vital to understand. The weight and the tensile strength of the specimen $A$ is considered as the benchmark, which is $100 \%$ to explain this phenomenon. The change in weight and the tensile strength concerning the benchmark shown in Table 3, which is also graphically represented in Fig. 10 . In case of single infill density, it is quite evident that the tensile strength 
Fig. 9 Comparison of Izod and Charpy impact test with weight of the specimen

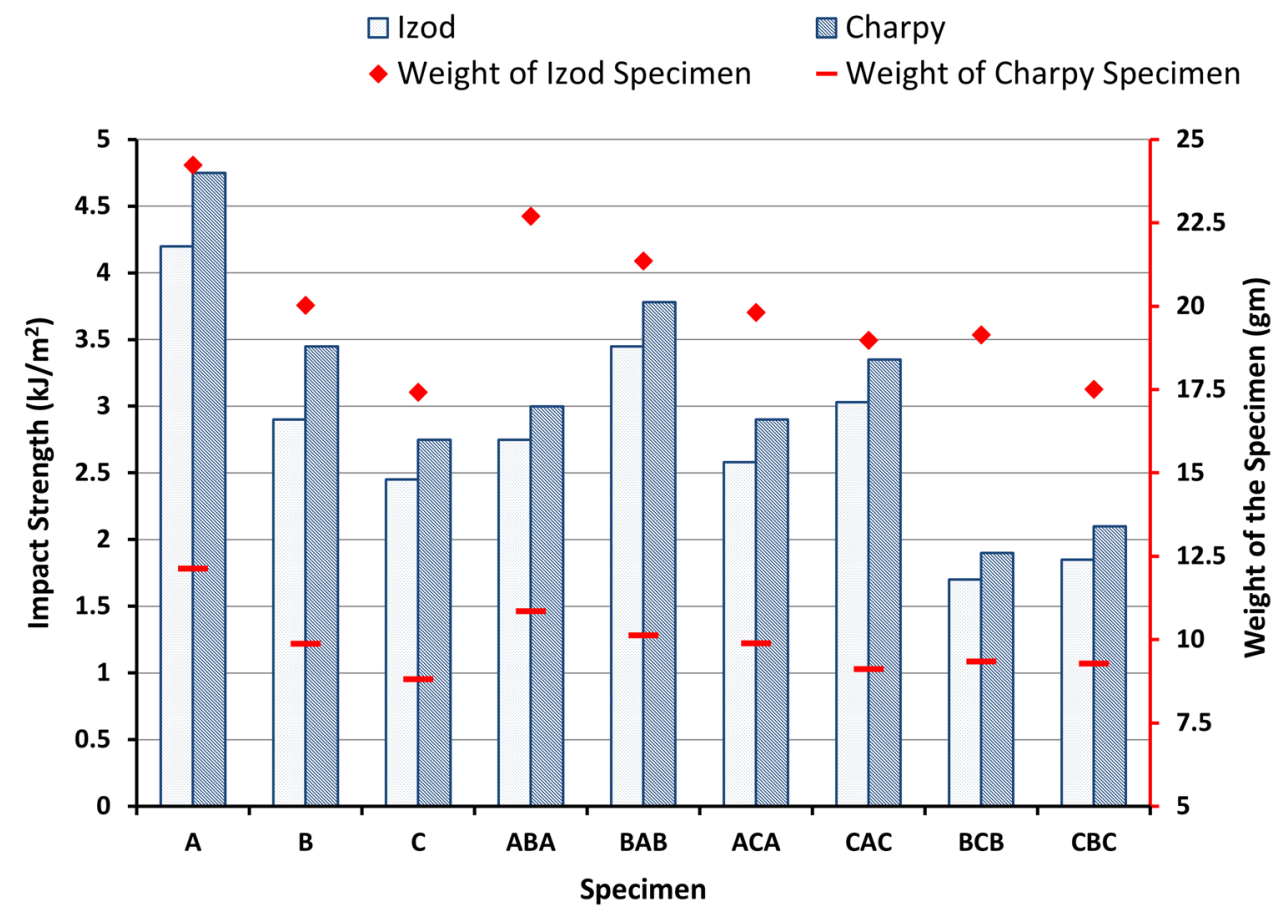

\begin{tabular}{lllllc}
\hline S. no. & Classification & $\begin{array}{l}\text { Strength (N/ } \\
\left.\mathrm{mm}^{2}\right)\end{array}$ & $\begin{array}{l}\text { Relative strength } \\
\text { percentage change }\end{array}$ & Weight (g) & $\begin{array}{l}\text { Relative weight } \\
\text { percentage } \\
\text { change }\end{array}$ \\
\hline 1 & A & 46.60 & 100.00 & 3.61 & 100.00 \\
2 & B & 35.45 & 76.07 & 3.01 & 83.32 \\
3 & C & 29.90 & 64.16 & 2.60 & 71.95 \\
4 & ABA & 48.20 & 103.43 & 3.42 & 94.87 \\
5 & BAB & 46.75 & 100.32 & 3.36 & 93.07 \\
6 & ACA & 44.70 & 95.92 & 3.37 & 93.27 \\
7 & CAC & 36.30 & 77.90 & 3.14 & 86.95 \\
8 & BCB & 38.65 & 82.94 & 3.16 & 87.41 \\
9 & CBC & 38.75 & 83.15 & 3.07 & 84.91 \\
\hline
\end{tabular}

Table 3 Relative percentage change of weight and tensile strength of specimen results depict that the tensile strength of the 3D printed part mainly depends on the two factors. Firstly, the denser infill density at the outer periphery and secondly on a lesser dense infill density at the inner region. The dense outer shell provides resistance from crack propagation, whereas, sparse-dense infill provides better flexibility, which eventually enhances the tensile strength of the specimen. The sequence of the specimen, according to $S W R$, is $A B A, B A B$ and $A C A$.

The percentage change in the weight and the impact resistance (Izod and Charpy) of the specimens represented tabular and graphical in Table 4 and Fig. $11(a, b)$, respectively. Both the figures show an identical change 
Fig. 10 Strength to weight ratio, percentage change of weight and tensile strength of the specimen

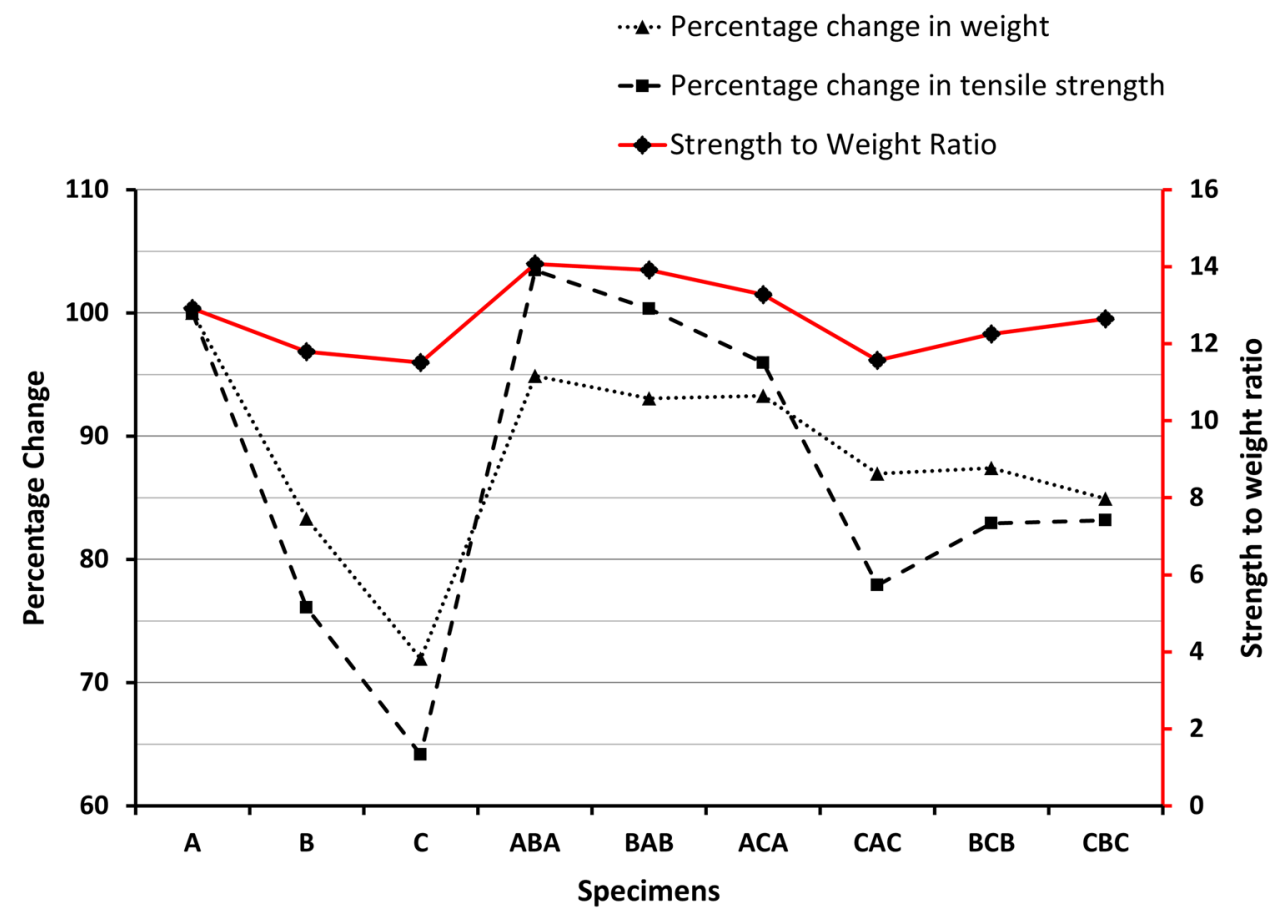

Table 4 Relative percentage change of weight and impact strength of specimen

\begin{tabular}{|c|c|c|c|c|c|c|c|c|c|}
\hline S. no. & Classification & $\begin{array}{l}\text { Izod } \\
\text { strength } \\
\left(\mathrm{kJ} / \mathrm{m}^{2}\right)\end{array}$ & $\begin{array}{l}\text { Relative } \\
\text { strength } \\
\text { percentage } \\
\text { change }\end{array}$ & Weight (g) & $\begin{array}{l}\text { Relative } \\
\text { weight } \\
\text { percentage } \\
\text { change }\end{array}$ & $\begin{array}{l}\text { Charpy } \\
\text { strength } \\
\left(\mathrm{kJ} / \mathrm{m}^{2}\right)\end{array}$ & $\begin{array}{l}\text { Relative } \\
\text { strength } \\
\text { percentage } \\
\text { change }\end{array}$ & Weight (g) & $\begin{array}{l}\text { Relative weight } \\
\text { percentage } \\
\text { change }\end{array}$ \\
\hline 1 & $A$ & 4.2 & 100.00 & 24.23 & 100.00 & 4.75 & 100.00 & 12.12 & 100.00 \\
\hline 2 & B & 2.9 & 69.05 & 20.02 & 82.64 & 3.45 & 72.63 & 9.87 & 81.42 \\
\hline 3 & C & 2.42 & 57.62 & 17.42 & 71.91 & 2.75 & 57.89 & 8.80 & 72.61 \\
\hline 4 & $A B A$ & 1.7 & 40.48 & 19.14 & 79.01 & 3.00 & 63.16 & 10.84 & 89.42 \\
\hline 5 & $\mathrm{BAB}$ & 1.85 & 44.05 & 18.57 & 76.66 & 3.75 & 78.95 & 10.12 & 83.48 \\
\hline 6 & $A C A$ & 2.58 & 61.43 & 19.82 & 81.80 & 2.90 & 61.05 & 9.88 & 81.48 \\
\hline 7 & CAC & 3.15 & 75.00 & 17.50 & 72.24 & 3.50 & 73.68 & 9.11 & 75.19 \\
\hline 8 & $\mathrm{BCB}$ & 2.75 & 65.48 & 22.70 & 93.70 & 1.90 & 40.00 & 9.34 & 77.05 \\
\hline 9 & $\mathrm{CBC}$ & 3.54 & 84.29 & 21.35 & 88.13 & 2.10 & 44.21 & 9.27 & 76.47 \\
\hline
\end{tabular}

pattern, when the percentage change in the weight and the impact strength is considered, When specimen $A, B$, and $C$ are considered, the experimental results represent a linear relationship between impact strength and the weight due to infill density. Specimen A with 100\% infill density represents the highest impact strength. However, the next better impact strength of $84.29 \%$ (Izod) and $78.95 \%$ (Charpy) with a relative weight of $88.13 \%$ (Izod) and $83.13 \%$ (Charpy) is found in specimen BAB when the combination of infill density is considered. Further down the list, the third best impact resistance is found to be $75 \%$ (Izod) and $73.68 \%$ (Charpy) in specimen CAC with relative weight of $72.24 \%$ (Izod) and $75.19 \%$ (Charpy). The order of the specimens according to the impact strength is $A, B A B$, and CAC. The strength to weight ratio curve in Fig. 11(a, b). In case of impact test, the SWR value is multipled with a factor one hundred. The SWR value of Charpy impact test is found better than lzod impact test, due to the support type. The curve represent the highest SWR value of specimen A which is 17.33 (Izod) and 39.18 (Charpy). SWR value is further reduced by considering any combination of infill density. The highest SWR value among the combined infill density specimen is of specimen $B A B$ which is 16.15 (Izod) and 37.35 (Charpy) followed by specimen CAC 
Fig. 11 Strength to weight ratio, percentage change of weight and impact strength of the specimen, a Izod, b Charpy
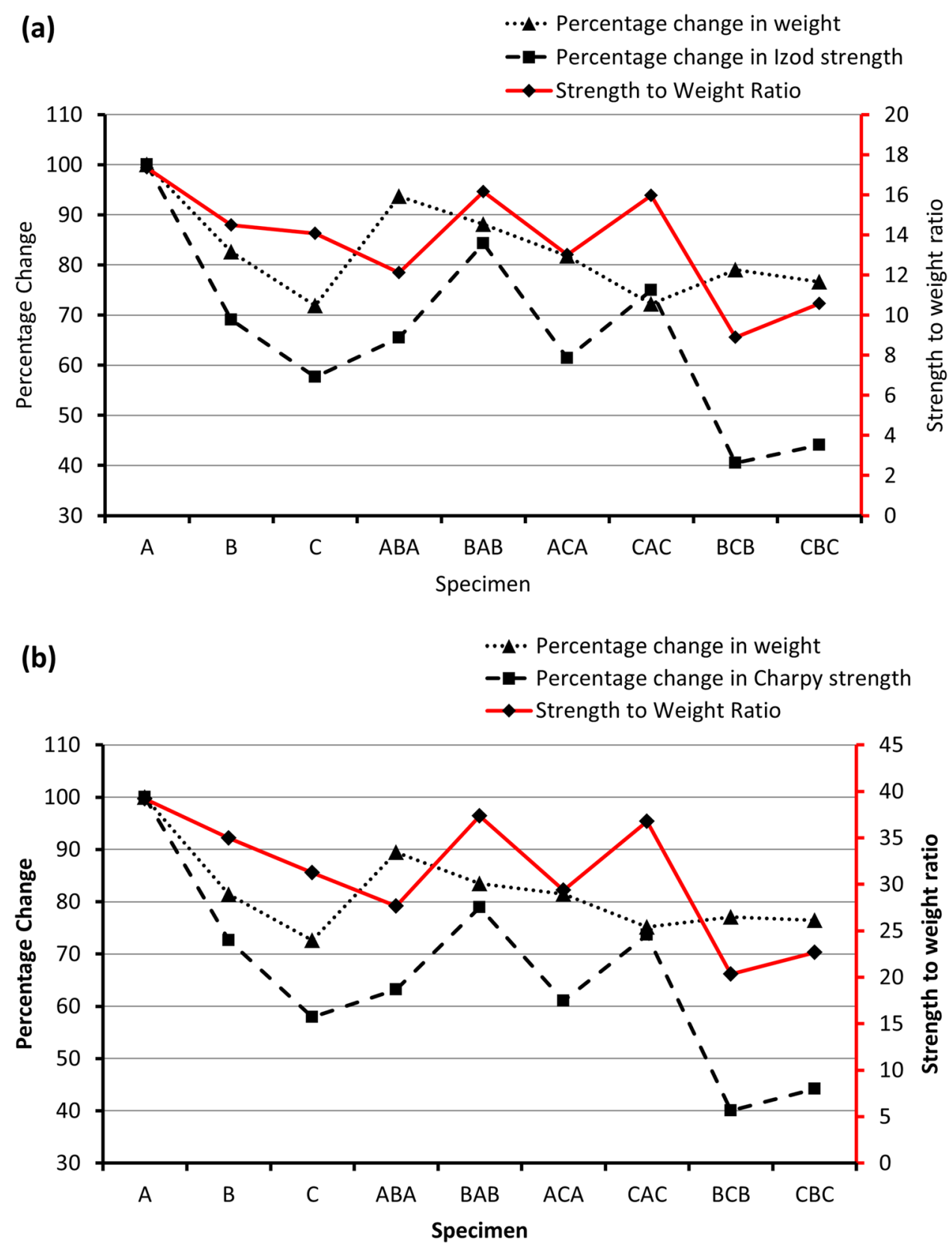

which is found to be 15.97 (Izod) and 36.75 (Charpy). The experimental data suggest that for better impact strength, the inner section must be most dense as compared to the outer section. This contrary behaviour of the impact specimen from the tensile specimen is due to the direction of the applied force.

The findings of the study are summarised as follows:

- The experimental data indicates that the higher tensile strength achieved by stacking layers of different infill density eventually reduces the raw material to an extent.
- The tensile strength of the specimens with variable infill density is increased by keeping dense infill at the outer periphery, and less dense infill at the inner area and this arrangement provides initial resistance to crack propagation on boundary and flexibility from the inner structure.

- The experimental data shows an increase of $10 \%$ Charpy impact strength as compared to lzod impact strength with a $50 \%$ reduction in the weight of the specimens.

- In the case of the impact test, the infill density is directly proportional to the impact strength, which results in 
the weight of raw material. The strength depletes by combining the varying infill density.

- Contrary to tensile strength, the impact strength increases if the inner layer is of higher infill density and outer shell are of lesser density.

\section{Conclusion}

Fused deposition modelling (FDM) is one of the important and commonly used technologies of 3D printing. The need was to identify process parameters that affect the mechanical behaviour of the built part. This study has the objective of investigating the effect of variable infill density on the tensile and impact strength of Polylactic Acid (PLA) specimens printed by an open-source 3D printer. The tensile and impact test specimen are made according to the DIN EN ISO 527-2, ASTM D256 (Izod) and ASTM D6110 (Charpy) respectively. In general, single infill density directly influences the tensile and impact strength of the 3D printed specimen. However, here in above mentioned situations, the tensile and the impact strength show a mixed response with combined infill density. The results obtained are useful for the selection of the appropriate weight of the 3D printed part, which will be undergoing a calculated tensile as well as impact loading. The present study helps to find the optimum strength to weight ratio for the PLA specimens printed by an open-source 3D printer.

The present work gives a good platform for future work as the influence of other factors along with variable infill density on the tensile and impact can also be considered. One can also study the orientation of the combinations. Other additional parameters like build orientation, the part layer thickness can also be combined for future applications and software development. The results can be more elaborative and conducive for further research with the use of an empirical relationship.

\section{Compliance with ethical standards}

Conflict of interest The authors declare that they have no conflict of interest.

\section{References}

1. ASTM International (2013) F2792-12a-standard terminology for additive manufacturing technologies. American Society for Testing and Materials, West Conshohocken, pp 10-12

2. Kumar L et al (2017) Rapid manufacturing: classification and recent development. Int J Adv Eng Res Sci 4(3):29-40

3. Roberson DA, Espalin D, Wicker RB (2013) 3D printer selection: a decision-making evaluation and ranking model. Virtual Phys Prototyp 8(3):201-212

SN Applied Sciences
4. Stanek M et al (2012) Rapid prototyping methods comparison. Int J Math Comput Simul 6(6):269-272

5. Kumar L et al (2018) 3D scanner integration with product development. Int J Eng Technol 7(2.13):220

6. Fodran E, Koch M, Menon U (1996) Mechanical and dimensional characteristics of fused deposition modeling build styles. Solid Freeform Fabr Proc 1996:419-442

7. Sood AK, Ohdar RK, Mahapatra SS (2010) Parametric appraisal of mechanical property of fused deposition modelling processed parts. Mater Des 31(1):287-295

8. Masood SH, Mau K, Song WQ (2010) Tensile properties of processed FDM polycarbonate material. Mater Sci Forum 654-656:2556-2559

9. Li H et al (2002) The effect of process parameters in fused deposition modelling on bonding degree and mechanical properties. Rapid Prototyp J 24(2):80-92

10. Tymrak BM, Kreiger M, Pearce JM (2014) Mechanical properties of components fabricated with open-source 3-D printers under realistic environmental conditions. Mater Des 58:242-246

11. Young $A$ et al (2017) Experimental characterization of the mechanical properties of 3D-printed ABS and polycarbonate parts. Rapid Prototyp J 23(4):811-824

12. Ziemian C, Sharma M, Ziemi S (2012) Anisotropic mechanical properties of ABS parts fabricated by fused deposition modelling. In: Gokcek M (ed) Mechanical Engineering, 1st edn. IntechOpen, London, pp 159-180

13. Torres J et al (2016) An approach for mechanical property optimization of fused deposition modeling with polylactic acid via design of experiments. Rapid Prototyp J 22(2):387-404

14. Ouhsti M, El Haddadi B, Belhouideg S (2018) Effect of printing parameters on the mechanical properties of parts fabricated with open-source 3D printers in PLA by fused deposition modeling. Mech Mech Eng 22(4):895-907

15. Dan BT et al (2018) Mechanics of additive and advanced manufacturing. In: Conference proceedings of the society for experimental mechanics series, the effect of the 3-D printing process on the mechanical properties of materials bobby, vol 9, pp 91-99

16. Chacón JM et al (2017) Additive manufacturing of PLA structures using fused deposition modelling: effect of process parameters on mechanical properties and their optimal selection. Mater Des 124:143-157

17. McLouth TD et al (2017) The impact of print orientation and raster pattern on fracture toughness in additively manufactured ABS. Addit Manuf 18:103-109

18. Uddin MS et al (2017) Evaluating mechanical properties and failure mechanisms of fused deposition modeling acrylonitrile butadiene styrene parts. J Manuf Sci Eng Trans ASME 139(8):1-12

19. Anderson I (2017) Mechanical properties of specimens 3D printed with virgin and recycled polylactic acid. 3D Print Addit Manuf 4(2):110-115

20. Lanzotti A et al (2015) The impact of process parameters on mechanical properties of parts fabricated in PLA with an opensource 3-D printer. Rapid Prototyp J 21(5):604-617

21. Rodríguez-Panes A, Claver J, Camacho AM (2018) The influence of manufacturing parameters on the mechanical behaviour of PLA and ABS pieces manufactured by FDM: a comparative analysis. Materials 11(8):1333

Publisher's Note Springer Nature remains neutral with regard to jurisdictional claims in published maps and institutional affiliations. 